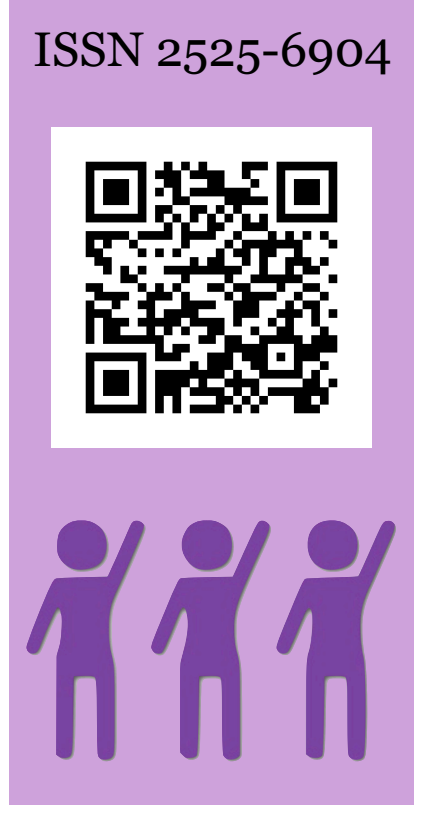

RESENHAS

\title{
Ironias sertanejas
}

Sobre os vazios e arbítrios de "Bacurau"

Thiago Cazarim da SiLva, Instituto Federal de Goiás

BACURAU. Direção de Kleber Mendonça Filho; Juliano Dornelles. Brasil/França: Vitrines Filmes, 2019. (131 min.), son., color.

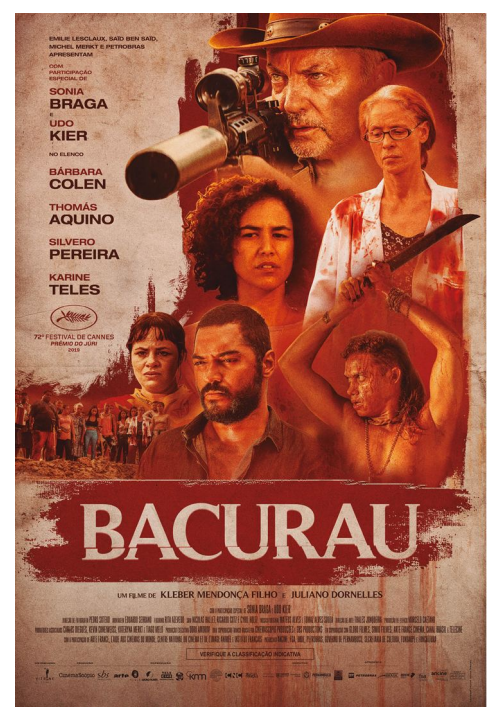

O presente texto tenta apresentar uma resenha do multipremiado filme Bacurau (Kleber Mendonça Filho e Juliano Dornelles) tomando como ponto de partida a apreciação negativa do referido filme feita pelo crítico de cinema Miguel Forlin (2019) no caderno Estado da Arte, do Estadão. Advirto antecipadamente, porém, que não se trata de uma mera defesa de Bacurau ou refutação de Forlin, mas sim de um confronto (crítico) da crítica com seu objeto, no qual certas redundâncias talvez precisem se afirmar para recuperar aquilo que, no segundo, tenha escapado à primeira.

A crítica de Forlin abordar os procedimentos fílmicos da lógica e estruturação narrativa, da composição e mise-en-scène das personagens, da trilha sonora, das convenções de gênero (western) e, por fim, da relação de Bacurau com as evoluções históricas do cinema nacional. No geral, a posição do crítico se constrói pelo signo do acaso e do vazio. Quanto à crítica da lógica narrativa do filme, o crítico escreve: "Nas mãos da dupla [de diretores], alguns dos mais diversos aspectos da criação cinematográfica, reunidos de maneira parcialmente arbitrária em razão de critérios vários e aleatórios das suas formações individuais, se tornam 
tintas jogadas displicentemente numa tela branca, jamais comunicandose entre si ou criando uma mistura que funcione dentro de uma lógica interna própria" (FORLIN, 2019). O tom impiedoso segue presente na análise da forma de apresentação das personagens: "A linguagem muitas vezes televisiva, apoiada numa mise-en-scène que explora a aparência e não a presença física dos atores [...]”; “[...] um grupo de personagens [...] termina por ser um conjunto de seres humanos esvaziados [...]" (FORLIN, 2019). Da mesma forma é que Forlin se refere à construção da trilha sonora:

Retirados dos contextos literário e cinematográfico nos quais estão inseridos [...], os versos [de Réquiem para Matraga] "Se alguém tem que morrer/ Que seja para melhorar" não pontuam mais a violenta existência de um protagonista complexo, mas sim a perspectiva infantil de dois diretores que negligenciam o peso de suas escolhas; os sintetizadores à la John Carpenter padecem do mesmo vazio referencial [...] (FORLIN, 2019).

Ainda, ao criticar o modo de emprego das convenções do gênero cinematográfico western, diz:

O western [....], que Glauber Rocha uniu ao tom operístico de Luchino Visconti e tornou o gênero por excelência de uma mitologia popular fortemente nacional e épica, ou que, na obra de outros diretores, como na de Nelson Pereira dos Santos, ganhou traços específicos e mais íntimos, retorna, décadas depois, a uma representação pueril, que se caracteriza quase que exclusivamente pelo confronto dos moradores contra os forasteiros, se mostrando conformada em copiar preguiçosamente um modelo estrangeiro [...] (FORLIN, 2019).

Diante do exposto, seria lícito interrogar se Forlin teria razão em sustentar que Bacurau traz a marca do arbítrio e do vazio referencial. Gostaria de argumentar que sim, ainda que num sentido e com conclusões bastante divergentes do analista. E uma chave para compreender o problema pode estar na própria crítica de Forlin, quando escreve o seguinte (grifo meu):

A atenção tímida dada à cultura daquela região [Bacurau] e o olhar direcionado a alguns dos seus aspectos mais exóticos são consequências naturais dessa barafunda, que nada tem de artística. Não parece existir um interesse real por aquelas figuras, apenas um interesse distanciado, muito mais voltado ao que elas podem representar do que ao que elas realmente são, sentem e pensam. Quem são os moradores de Bacurau? Pelo filme, não sabemos, pois só temos a imagem de homens e mulheres se 
reunindo para vencer uma guerra. Quem são os estrangeiros? Também não sabemos, pois só vemos homens e mulheres se unindo para participar de um jogo doentio [...] (FORLIN, 2019).

Tal chave de leitura reside, pois, na distância entre representação e essência, propriedade e impropriedade - ou, dito de outro modo, na diferença entre o que as personagens são capazes de referir para fora do filme (eis o sentido de representar: apontar para o que não está presente, tomando-lhe o lugar de direito), e o que elas são em si mesmas, de direito e por mérito próprio.

O que seria, então, próprio a Bacurau? Se o arbítrio parece marcar o emprego de convenções de gêneros cinematográficos diversos (e Forlin menciona acertadamente a presença de menções à ficção científica no filme), trilha sonora e construção de personagens, é por ele, e não à sua revelia ou margem, que o vazio referencial de Bacurau deveria ser pensado. Quando Kleber de Mendonça Filho e Juliano Dornelles emolduram uma narrativa da invasão e da oposição entre o próprio (residentes de Bacurau) e o impróprio (sudestinos e estadunidenses), não é pela simples cópia preguiçosa da oposição entre mocinhos e bandidos, entre xerifes/caubóis/colonizadores e nativos/ indígenas. Bacurau, ao contrário do que afirma Forlin, talvez sequer devesse ser visto como retrato do Brasil, ou mesmo do Nordeste. Isso porque, se há um vazio referencial e um arbítrio como orientação geral do filme, não faria sentido sequer imaginá-lo sob o signo da representação. Entendo que Bacurau não retrata uma guerra entre Brasil e forças estrangeiras, mas, ao contrário da lógica da invasão, trabalha a ideia de uma "evasão" do sertão mais sutil por meio do apagamento da distância entre o local e o externo, o próprio e o impróprio. Esse esvaziamento referencial está profundamente ligado com a noção de sertão, que não diz respeito a um espaço enclausurado ou perfeitamente localizado.

Talvez pareça óbvio apontar que Bacurau não retrata nada realmente existente, dado o cenário realista-fantástico ou de distopia soft que permeia todo o filme. $\mathrm{O}$ que parece ser contraintuitivo é dizer que Bacurau não se localiza num sertão como equivalente de um ponto no mapa do Nordeste, este último oposto tanto aos Estados Unidos quanto ao "Sul" (que, na linguagem de muitos nordestinos retratados no cinema nacional, e pelos próprios personagens sudestinos de Bacurau, é tudo aquilo que fica a leste de Goiás e ao sul da Bahia). Porém, não é em 
relação a um lugar real externo ao filme, e sim à dinâmica intranarrativa que me volto para pensar a oposição "dentro/fora".

Ao contrário da imagem clássica dos retirantes que fogem da seca, consagrada midiaticamente e em peças literárias como Morte e Vida Severina, a cidade de Bacurau é um espaço sertanejo estruturado em torno de uma modernização muito peculiar, entrecortada pela resistência do verde em meio à aridez geográfica e política. É nesse cenário-paisagem que seus habitantes tanto permanecem quanto encontram um ponto de retorno. Isso porque, mesmo para as personagens cujas vidas dependem, em alguma parte, da saída de Bacurau, isso não se dá na forma de uma fuga para o "Sul", e sim conforme elas se espalham a partir de Bacurau sem que "Sul" lhes seja uma referência norteadora. A categoria "sertão" me parece aqui muito adequada para pensar o lugar Bacurau porque, se numa leitura imediatista vemos a expulsão do estrangeiro e do forasteiro quando adentram o sertão, por outro lado podemos ver também que o sertão já encontrou, por seus meios próprios, sua infiltração no resto do território de um país. A cena do velório de Carmelita, no qual sua prole é descrita em sua diáspora pelo mundo, mostra que o lugar Bacurau se caracteriza por sua capacidade de espraiamento e dispersão. "Sertão" é exatamente a categoria que permite pensar, ao mesmo tempo, uma aparente resistência ao forasteiro/invasor ao lado da capacidade de se infiltrar e multiplicar espacialmente. Basta pensarmos na chamada música sertaneja: ela recobre um território que vai do semi-árido ao Pantanal, vai quase do litoral nordestino à fronteira com o Paraguai, englobando localidades rurais do Paraná, São Paulo, Minas Gerais e Goiás, bem como gêneros musicais de vários pontos da América Latina no "local" "sertão". Bacurau é construída, sim, com elementos de um sertão nordestino; mas este sertão é o sertão que também se espalha e metamorfoseia sem deixar de ser sertão nos diversos territórios que ocupa. Bacurau é o sertão que atravessa o território, não o local oposto ao pretenso autodeclarado universal (Sudeste) ou o particular oposto ao genérico ("Sul"). É por esse apagamento da oposição entre local e estrangeiro que o sertão se afirma como força englobante ${ }^{1}$ que atua em sua dispersão e metamorfose territorial e cultural. Nada mais incorreto

1 Termo utilizado pela pesquisadora Imani Perry (2004) para pensar o modo como o hip-hop aglutina, em vez de opor, elementos discrepantes e incompatíveis: o sagrado e o profano, a crítica e a festa, tradição e inovações tecnológicas. 
que insistir na dualidade entre forasteiro e "indígena" (no sentido de nativo, interno a um espaço delimitado), pois.

Esta explicação parece pouco convincente quando pensamos que Bacurau é acossada pelo estrangeiro, que só pode tentar dominá-la apagando seus sistemas de localização fixa (mapa oficial, sinal de telefone). E aqui cabem algumas ponderações. Em primeiro lugar, devemos perceber que são dois os sistemas de dispersão de localização de Bacurau, um no sentido da metamorfose, outro no sentido do apagamento estrangeiro. Bacurau trabalha cinematograficamente o embate entre ambos, mas é preciso perceber que isso só se torna possível quando o prefeito Tony Jr. tenta introduzir o estrangeiro como força de aniquilação do local. Esse é um perigo real da modernização, contra o qual Bacurau aposta numa organização heteróclita dos elementos que, num momento impossível de localizar no filme, já lhe foram externos: o grupo de "Zap" (como recurso de comunicação estrangeiro), o museu (como dispositivo colonial), ou então o vídeo viral (comum em redes sociais), o carro de som e vídeo do DJ Urso (e a própria nomenclatura "Urso" remete à cultura gay bear - urbana e originada no estrangeiro²). Bacurau põe em relevo, então, não apenas a dispersão geográfica do sertão, mas também os modos de fazer o estrangeiro funcionar no sertão e as condições em que o sertão não se dobra ao que vem de fora. Algo muito distante, por isso, de uma oposição esquemática entre próprio e impróprio, "indígena" e forasteiro.

Se Bacurau, no mesmo gesto, cita e esvazia elementos diversos, o faz como recurso irônico de uma perspectiva analítica ancorada no compromisso com a lógica binária da invasão/resistência. Ironia aqui é pensada como recurso poético do ato de dizer algo dissimulando o sentido do que se diz. Esse "algo" que é dito ironicamente é o conjunto de elementos citados e esvaziados referencialmente, o que é preciso interpretar num prisma diverso de Forlin. Embora este detecte corretamente que o invasor estrangeiro trate Bacurau como tabuleiro de um jogo violento, penso que não tenha compreendido bem o alcance desse ludismo, assim como não tenha percebido que é como apreço lúdico pelo risco de invasão que a cidade de Bacurau encara a entrada do estrangeiro em sua territorialização.

2 Igualmente, não é como agente externo que as personagens LGBTQ têm lugar em Bacurau. O queer cangaceiro Lunga mostra que o sertão tem seu modo próprio de fabricar a vida diversa. 
Isso se mostra de forma mais evidente, por exemplo, no repente nordestino dirigido aos sudestinos enviados para confirmar o apagamento referencial de Bacurau dos sistemas de localização (mapa, sinal de telefonia móvel e internet). Os sudestinos são cantados, são citados diante de si mesmos em tom jocoso, para marcar a desconfiança sertaneja. Desconfiança que se mostra a quem é sua causa de modo enviesado, disfarçado, para não espantar ou expulsar violentamente, e sim apenas para demarcar o ponto máximo de aproximação tolerável.

Igualmente, o emprego das convenções do western em Bacurau não é uma celebração de "[...] um gênero que, por muitos anos, relativizou o genocídio indígena [...]" (FORLIN, 2019). O faroeste sertanejo neste filme, citando as convenções de um gênero no qual o ato de assassinar arbitrariamente habitantes próprios de uma localidade, esvazia a referência genocida, invertendo o resultado de uma pretensa invasão. Se toda a cidadela de Bacurau se reúne para eliminar seus agressores, isso se dá pela aceitação crítica do jogo, e não por sua perpetuação mimética. Aqui Forlin peca por esperar de um cenário de guerra uma solução "íntima" ou "operística”, tanto quanto por não compreender que o bang-bang, da perspectiva dos nascidos em Bacurau, não tem o sentido de um jogo prazeroso, e sim inescapável. Quando os termos do englobamento sertanejo do estrangeiro são recusados por este último em favor de uma tentativa de invasão bruta - invasão pelo simples desejo de invadir e ocupar que é o pano de fundo de toda peça artística que elogia efetivamente a colonização -, então ao sertanejo, tratado como colonizável e exterminável, resta entrar no jogo para inverter seu desfecho. Se o forasteiro é aquele que recusa negociar e englobar igualitariamente o sertanejo (e basta lembrar da recusa dos sudestinos em adentrar o museu de Bacurau), é ele quem cria a lógica da oposição e da invasão, jamais o "indígena". Retomar o gênero western, citando largamente suas convenções e clichês, serve a Kleber de Mendonça Filho e Juliano Dornelles para esvaziar o elogio do genocídio e da lógica da invasão. $\mathrm{E}$ isso mesmo quando, no final do filme, o forasteiro-mor não é exterminado, mas aprisionado: do comandante da invasão, não se dá a imagem de sua morte, e sim de seu enterro. Talvez como num ritual antropofágico, em que o líder rival está à altura o bastante para ser deglutido e incorporado aos guerreiros locais, ou então como se Bacurau o retivesse para transformá-lo em adubo e nutriente da terra. Não em vão, a miragem-“viagem” de um caixão, de um repositório da morte, presente no início do filme, é transformada e também citada 
sutilmente no final do filme, em que o estrangeiro-mor, duplamente estrangeiro (europeu e norte-americano), vai para baixo da terra vivo. Algo, também, bastante distante da lógica arbitrária, estrangeira, da invasão e do extermínio.

Em Bacurau, a dualidade entre "indígenas" e forasteiros não se expressa, portanto, somente na forma de um antagonismo ou na oposição entre atividade estrangeira e passividade nativa. Tampouco tal dualidade tem a forma de um apagamento total das individualidades das personagens, apresentadas sempre de soslaio pelos diretores. Aqui vale mencionar novamente a estratégia dos habitantes de Bacurau em utilizar o grupo de "Zap" como estratagema de se esconder de Tony Jr.: esconder-se justamente do colaboracionismo oportunista de um político pouco disposto a se deixar penetrar pelo movimento sertanejo de espraiamento e infiltração. Tony Jr., ele mesmo, é um invasor-"indígena", o estrangeiro-nativo para o qual o sertão não é senão um espaço cercado de expropriação e interesse eventual. Da mesma forma, os sudestinos que se recusam a adentrar o Museu de Bacurau representam o estrangeiro-forasteiro, o invasor stricto sensu que não tem interesse em se afetar pelo território que ocupa. Para estes sujeitos, os habitantes de Bacurau se escondem, de fato; e que a direção do filme dê pouco espaço a desenvolvimentos psíquicos mais profundos não é uma falha narrativa, e sim uma forma de mostrar que o sertanejo não está, diante do estrangeiro, passivo. O sertão se mostra somente em igualdade de condições - mesmo que seja na condição extrema de uma violência como jogo de gato e rato.

Por fim, o arbítrio e o esvaziamento referencial, longe de serem defeitos de Bacurau, são seus eixos estruturantes por excelência. Isto é, se aceitarmos que o arbítrio é criticado pela ironia do estrangeiro e a ele devolvida, e se compreendermos que Bacurau se desenvolve pela disputa complexa e nada maniqueísta entre o esvaziamento referencial calculado das assimilações culturais próprias - não impostas - do estrangeiro, de um lado, e a resistência a imposições violentas - impróprias e indesejadas pelo sertanejo. Se Bacurau e os habitantes da cidade homônima ressignificam as referências estrangeiras, ora no registro da desconfiança e da recusa tática irônica, ora pela assimilação e apropriação ativas, não é para repetir o arbítrio que, impropriamente, assola o movimento de metamorfose própria do sertão.

Exatamente por essa razão, seria insuficiente ler em Bacurau um manifesto de resistência política. Não porque o sertanejo se renda ao 
invasor - muito pelo contrário. Contudo, a ideia de resistência turva o entendimento de como Bacurau é lugar também da aglutinação e deglutição do estrangeiro. Talvez o espectador do filme encontre nele uma revisão da antropofagia, de uma perspectiva muito diferente da elite intelectual e artística da Semana de Arte Moderna de 1922. Talvez mesmo essa seja a última ironia posta por Kleber Mendonça Filho e Juliano Dornelles: aquela da antropofagia modernista sudestina que já serviu largamente para pensar a identidade nacional brasileira. A antropofagia de Bacurau, citando quase de soslaio a modernista paulista, a ironiza recusando uma assimilação feita de qualquer modo bem entendido, de um modo folclorizante. O sertanejo - que nunca diz que nome do cidadão nativo de Bacurau, que se recusa a colocar um nome próprio na boca do estrangeiro - recoloca a assimilação cultural do invasor no patamar de um jogo sempre esquivo no qual não é possível se entregar e ao qual tampouco se pode resistir totalmente a reelaborar. Somente permeável e teimoso como o curso de um rio em cheia, e mesmo nas tentativas de represá-lo e dominá-lo pela força bruta, o sertanejo incorpora as comportas que lhe impõem como parte de seu curso. Não exatamente resistência - não por faltar atividade ao sertanejo, e sim pela esquiva constante de tomar o exterior como algo impróprio, quer dizer, aquilo que não é apropriável, digerível e reelaborável nos termos do próprio sertão. O sertanejo de Bacurau, aquele que não entrega o que há de mais próprio - seu nome, seu território, sua presença diante do oportunista -, digere a invasão como parte de sua forma de persistir vivo.

\section{Referências}

FORLIN, M. A baixeza de Bacurau. Estadão. 30 ago. 2019 (online). Disponível em: <https://cultura.estadao.com.br/blogs/estado-da-arte/a-

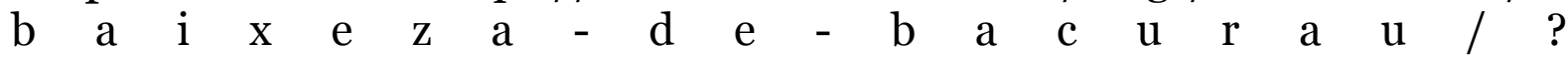
fbclid=IwAR3hVuRVfhYTzuCoI24ppdyhk12NJ5UpLc9lPYpgeIonRcT1rAW1ylw EeFQ >. Acesso em: 30 set. 2019.

PERRY, Imani. Prophets of the hood: politics and poetics in hip-hop. Durham/London: Duke University Press, 2004. 